\title{
The effects of self-assertiveness and appearance satisfaction on psychological well-being
}

\author{
Heawon Park* and Myungsun Chung ${ }^{\dagger}$ \\ Dept. of Clothing \& Textiles, Chonnam National University, Korea* \\ Human Ecology Research Institute, Chonnam National University, Korea \\ 자기주장성과 외모만족이 심리적 안녕감에 미치는 영향 \\ 박 혜 원*·정 명 선 ${ }^{\dagger}$ \\ 전남대학교 의류학과*, 전남대학교 생활과학연구소
}

\begin{abstract}
This study aimed to investigates the effects of self-assertiveness and appearance satisfaction on psychological well-being (personal growth, purpose in life, self acceptance, environmental mastery, autonomy and interpersonal relations), and find out if there exists any causal relationship among each variable in the process. For data collection, a questionnaire was administrated from April 23 to May 13, 2012 in the city of Gwangju, Korea. The subjects were women in their twenties and thirties. 359 women responded to it. The results were as follows. First, overall self assertiveness had positive effects on appearance satisfaction which, in turn, turned out to have overall positive effects. Second, the overall effects of self assertiveness on psychological well-being turned out to have positive effects. Third, overall appearance satisfaction had positive effects on psychological well being. Forth, the effects that self assertiveness had on psychological well-being mediated appearance satisfaction and appeared to be partly insignificant. The implications and the direction of this research should be discussed in the future study so that it can improve personal psychological well-being by finding out other variables aside from self assertiveness, appearance satisfaction.
\end{abstract}

Keywords: self assertiveness(자기주장성), appearance satisfaction(외모만족), psychological well-being(심리적 안녕감)

\section{Introduction}

오늘날 지속적인 과학의 발달로 인해 인간수명
이 점차 길어짐에 따라 사람들의 관심은 어떻게 하 면 더 오래 건강하고 행복한 삶을 누릴 것인가에 쏠리고 있고, 모든 생활국면에서 웰빙이라는 용어 가 일상적으로 사용되고 있다. 주로 ‘안녕감’으로

Received 11 August 2014, revised 13 October 2014, accepted 13 October 2014.

본 논문은 박사학위청구논문의 일부임.

${ }^{\dagger}$ Corresponding author (mschung@chonnam.ac.kr)

This is an Open Access article distributed under the terms of the Creative Commons Attribution Non-Commercial License (http://creativecommons.org/licenses/by-nc/3.0) which permits unrestricted non-commercial use, distribution, and reproduction in any medium, provided the original work is properly cited. 
번역되어 사용되는 웰빙(well-being)은 'well(건강한, 만족스러운, 좋은)'과 'being(삶, 존재, 생명)'의 합 성어로 삶의 질(quality of life)로 지칭되기도 하는 개념이며(Kim, 2010), 환경, 신체 및 마음 혹은 정 신의 모든 국면이 가장 조화롭고 만족스런 상태를 의미한다(Kim, 2004).

심리적 안녕감 혹은 삶의 질에 관련된 국내 연구 는 1990년대 초반부터 심리학, 간호학, 체육학, 교 육학 분야에서 수행되기 시작했으며, 그 결과 심리 적 안녕감에 영향을 미치는 변인들이 파악되어 왔 고(Eom, 2001; Gong, 2009; Hong, 1998; Ju, 2011; Kim, 1993; Kwon, 2008; Yook et al., 2009), 심리적 안녕감 증진을 위한 프로그램이 개발되어 다양한 집단의 삶의 질 혹은 만족을 향상시키는 데에 기여 하고 있다(Kim, 2006).

한편, Havighurst(1972)는 한 개인의 심리적 안녕 감은 그 사람이 유지하고 있는 대인관계의 질에 의 해 크게 좌우된다고 보았으며, 많은 사람들이 타인 들에게 자신을 어떻게 표현해야 할지 몰라 오해를 불러일으키거나 비상식적인 행동을 표출함으로써 원만한 대인관계를 형성하지 못하여 정신적인 고 통을 겪고 있다고 밝혔다. Song(1992)은 어떤 이유 로든 타인과 바람직한 관계를 형성하지 못할 경우, 불안, 우울, 욕구 좌절, 소외감 등 많은 부정적인 상 태를 경험하게 된다고 하였다.

실제로 우리는 타인과의 관계로 이뤄지는 사회 생활에서 우리의 말과 행동 및 타인에게 보여지는 신체적 외모를 관리함으로써 자신이 바라는 인상 을 타인에게 전달하고자 하며, 원만한 대인관계 형 성을 위해 자기제시 방법 및 자기노출과 자기감시 의 정도를 선택하고 있다. 특히 인간관계에 적용되 는 사회적 기술(social skill)들 중 하나로 간주되는 자기주장성(Bornstein et al., 1977)은 자기의 견해를 표현할 능력 혹은 자기의 견해와 일치하지 않는 견 해에 대해 찬성하지 않을 능력을 의미하며(Lawrence, 1970), 성취감과 자신감 및 심리적 안녕감에 영향 을 미치는 것으로 파악되고 있다(Heo 재인용, 2007).

그간 국내 의류학 분야의 외모관련 연구들은 주 로 일상적인 외모관리에서부터 위험을 내포하는 미용성형수술까지의 외모관리행동 실태를 파악하 고, 외모관리행동에 미치는 심리적 변인들과 사회
문화적 요인들의 영향을 파악하는 데에 초점을 맞 추어 왔다. 2000년대에 들어 의류학 분야의 연구자 들이 외모관련 연구에 자기주장성과 심리적 안녕 감이라는 개념들을 도입하기 시작하였고(Bae \& Park, 2011; Chung, 2004; Jung et al., 2008; Hwang \& Kim, 2006), 이러한 연구들은 타인들과의 관계로 이뤄지는 사회생활에서 언어나 행동을 통한 자기 주장이 비언어적 단서인 신체적 외모와 더불어 개 인의 심리적 안녕감에 영향을 미친다는 것을 부분 적으로 밝혀왔다.

이러한 연구들은 그간 여러 연구자들이 결과변 인으로 다뤄왔던 외모관리행동이 삶의 질 향상 혹 은 심리적 안녕감에 영향을 미치는 선행변인이라 는 관점을 제기한다. 즉, 인간의 모든 행동에는 동 기와 목적이 있다는 관점에서 볼 때, 우리 사회 남 녀노소의 적극적인 외모관리행동은 더 행복한 삶을 위한 목적 지향적인 행동으로 볼 수 있고, 여기에 투입되는 물질적-심리적 비용에 따라 결과에 대한 기대 수준과 그에 따른 외모만족의 정도가 다를 수 있다는 것이다. 따라서 개인의 자신의 외모에 대한 만족의 정도가 당연히 심리적 안녕감에 영향을 미 칠 것으로 가정할 수 있다. 그러나 의류학 분야에 서 언어나 행동을 통한 자기주장과 신체적 자기 제 시의 선행요건인 외모관리행동과 그에 따른 외모 만족이 심리적 안녕감에 미치는 영향을 포괄적으 로 파악하고자 한 연구는 아직 보고되지 않고 있다.

따라서 본 연구에서는 우선 개인의 자기주장성 과 외모관리행동의 결과로 볼 수 있는 외모만족이 각각 심리적 안녕감에 어떤 영향을 미치는가와 이 변인들 간 인과관계가 존재하는가를 구명하고자 하 였다.

\section{Theoretical Background}

\section{Psychological-wellbeing}

심리적 안녕감은 행복, 번창, 건강상태가 합치된 상태(Ha, 1991), 혹은 여러 가지 다양한 요인들이 통 합되어 나타나는 긍정적인 인지적, 정서적 상태(Yang, 1998b)로 정의되고 있다. Diener(1984)는 이러한 상 태를 지칭하는 데에 주관적 안녕감(subjective well-being) 이라는 용어를 사용하였다. 그러나 Ryff(1989)는 안 
녕감을 단순히 '행복감'으로 보는 주관적 안녕감이 라는 용어가 삶의 질이라는 의미를 지나치게 단순 화시킨다는 비판과 함께 심리학의 다양한 이론에 근거한 다차원적인 안녕감 모델(well-being model) 을 개발하여 그 척도의 타당성을 확인하였으며, 이 를 심리적 안녕감(psychological well-being; PSWB) 으로 지칭하였다. PSWB는 자기수용(self acceptance), 긍정적 대인관계(positive relations with others), 자 율성(autonomy), 환경통제력(environmental mastery), 삶의 목적(purpose in life) 및 개인적 성숙(personal growth)이라는 6개의 차원으로 분류된다. Kim et al. (2001)은 PSWB가 한국인의 심리적 안녕감을 설명 하는 데에 적합하다는 것을 확인하였다.

한편, Gong(2009)은 남녀 대학생들을 대상으로 한 연구에서 외모만족이 심리적 안녕감의 6 개 하위 차원 중 개인적 성숙을 제외한 5 개 차원에 유의한 영향을 미치고, 외모만족도가 심리적 안녕감의 많 은 부분을 설명한다는 것을 발견하였다. Yook et al. (2009)은 여대생들을 대상으로 한 연구에서 이상적 인 신체상과 실제 자신의 신체상의 불일치가 작을 수록 심리적 안녕감이 더 높아진다는 것을 발견하 였다. $\mathrm{Ju}(2011)$ 역시 남녀고등학생을 대상으로 한 연구에서 자신의 외모에 만족할수록 심리적 안녕 감이 더 높았다고 밝혔다.

최근 의류학 분야에서 Hwang and $\operatorname{Kim}(2006)$ 은 외모관리행동 유형에 따라 분류된 남녀대학생 외 모관리행동집단 간 신체이미지 및 심리적 안녕감 의 차이를 분석한 결과, 일상적 외모관리 집단이 삶의 목적, 자아수용, 자율성, 개인적 성장, 환경지 배력, 책임감 요인이 높게 나타나, 심리적으로 안정 적인 집단인 것으로 나타났고, 의복을 통한 외모관 리 집단은 자율성과 환경통제 차원의 심리적 안녕 감이 낮았으며, 과도한 약물 복용이나 과격한 체중 조절집단은 목표설정이나 자신에 대한 만족감, 개 인적 성장 정도가 낮은 것으로 나타났다고 밝혔다. Bae and Park(2011)은 판매 서비스직 여성들을 대 상으로 한 연구에서 심리적 안녕감과 네일행동간 관련성은 개인적 성숙 차원과 삶의 목적차원에서 관련성이 있다고 밝혔다.

\section{Self-assertiveness}

불안신경증 치료를 위한 이론적 근거로 자기주 장성 이론을 제시했던 Salter(1949)는 불안신경증 환 자들이 지나친 자기억제로 인해 고통을 받는다고 보고, 흥분반응의 필요성을 제기하였으며, 흥분성 훈련을 통해 긍정적인 느낌이든, 부정적 느낌이든 간에 자신이 느끼는 감정을 표정이나 말로 표현해 야 한다는 것을 강조하였다(Andrew 재인용, 1980). Wolpe and Lazarus(1966)는 주장행동을 사회적으로 수용될 수 있는 모든 권리와 느낌의 표현으로 보았 고(Hong, 1998), 거기에 분노, 초조, 반대 혹은 괴로 움뿐만 아니라, 애정, 즐거움 혹은 사랑 같은 긍정적 감정의 표현까지를 포함시켰다. Albert and Emmons (1975)은 자기주장성을 다른 사람의 권리를 침해하 지 않고, 타인과의 갈등 없이 자신의 관심사나 느 낌, 생각 등을 편안하고 솔직하게 말하거나 표현하 는 것으로 정의하였다.

Hong(1981)은 한국사회에서 ‘주장하다' 혹은 ‘주 장성'이라는 용어가 일반적으로 상대방의 감정이 나 입장을 고려하지 않고, 자기의 사상이나 감정을 강력하게 고집하는 것으로 이해될 소지가 있다고 보아 '주장행동' 대신 '자기 발표력' 혹은 '자기주 장성'이라는 용어의 사용을 권장했고, 다수의 국내 연구자들이 자기주장과 자기표현을 동일개념으로 사용하고 있다.

Lazarus(1971)는 자기주장성을 '아니오'라고 말 할 수 있는 능력, 호의를 요구할 수 있는 능력 및 긍정적, 부정적 느낌을 표현할 수 있는 능력으로 분류하여 제시하였고, 자기주장의 구체적인 프로그 램을 개발하여 최초로 실험연구를 수행하였다(Song 재인용, 1992). Hong(1981)은 한국사회에서 '주장 하다' 혹은 ‘주장성'이라는 용어가 일반적으로 상 대방의 감정이나 입장을 고려하지 않고, 자기의 사 상이나 감정을 강력하게 고집하는 것으로 이해될 소지가 있다고 보아, ‘주장행동' 대신 '자기 발표력' 혹은 '자기표현'이라는 용어의 사용을 권장했고, 다 수의 국내 연구자들이 자기주장과 자기표현을 동 일개념으로 사용하고 있다. Song and Yon (2008)은 자기주장성 훈련을 통해 자신의 느낌이나 생각을 솔직하고 정확하게 표현함으로써 대인관계와 의 사소통에서 만족감을 높일 수 있다는 것을 확인하 였다. 
한편, 자기와 외모와의 관련을 연구한 Thompson (1977)은 연극의 요소를 인상관리를 위한 연출법 (Dramaturgy)을 현실 상황과 대비시켜 구체적으로 제시하였다. 특히 자기주장(self-assertiveness)의 방 법이나 정도의 선택이 타인에게 전달하고자 하는 인상을 위한 전제조건인 동시에, 특히 인상형성의 가시적 단서가 되는 외모관리의 중요한 이유가 되는 것으로 볼 수 있다라고 하였다. 우리나라의 Chung (2004)은 20대 여성을 대상으로 한 연구에서 자기 주장성이 강하면 신체에 대한 관심과 의식이 높고, 자기주장성이 높을수록 외모만족도가 낮은 것으로 나타나, 자기주장성이 외모만족도와 외모관리행동 에 직접적인 영향을 미치지는 않았으나, 의복태도 와 신체만족도를 매개하여 외모관리행동과 신체노 출 의복행동에 영향을 미쳤다고 밝혔다. 또한 Mung and Park(2013)은 중년여성을 대상으로 자기표현이 외모관리행동에 미치는 영향에 관한 연구에서 전 반적인 외모관리행동에 자기주장성이 유의한 영향 을 미치는 것으로 나타났고 밝혔다. Eom(2001)은 자기주장성훈련 프로그램이 자기주장성 능력과 심 리적 안녕감에 미치는 영향을 검증하고자 한 연구 에서 자기주장성 훈련을 받은 상담집단이 자기주장 성 훈련을 받지 않은 통제집단에 비해 자신의 생각 이나 느낌을 있는 그대로 표현하는 능력과 심리적 안녕감이 더 높은 것으로 나타났다고 밝혔다. Kim (2011)은 여성들의 댄스 스포츠 참가를 통한 자기 관리 행동이 자기주장성에 긍정적인 영향을 미친 다는 것과 참가동기, 자기관리행동, 자기주장성 및 생활만족 간 인과관계가 있다고 밝혔다. 이러한 연 구들은 신체 혹은 외모에 대한 만족과 심리적 안녕 감 간 관련성이 있다는 것을 가정할 수 있게 한다.

\section{Appearance satisfaction}

우리는 특별히 의식하지 않으면서도 일상적으로 우리의 외모를 관리하고 있다. Myerson(1971)은 외 모관리를 단순히 사람들이 자신의 외모의 단점을 보 완하기 위해 노력하는 것으로 보았으나, Kaiser(1990) 는 외모관리행동을 외모와 관련된 모든 관심, 의사 결정 및 행동을 포괄하는 것으로 보았다. Kim and Lee(2007)는 자신의 외모에 대한 만족도를 높이기 위해 행해지는 행동을 외모관리행동으로 규정하였
고, Lee(2010) 역시 외모관리 행동을 자신의 신체적 외모에 대한 평가와 만족도를 향상시키기 위한 것 으로 보았다. 이러한 관점들에 비춰볼 때 외모에 대 한 만족을 외모관리행동의 결과 변인으로 보는 데 에는 무리가 없을 것으로 보인다.

한편, Sung(1997)은 외모만족을 개인이 정체감 을 형성하는 과정에서 얻게 되는 자신의 신체에 대 한 주관적인 평가로 보았으며, 이것이 개인의 삶에 대한 만족을 결정짓는 중요한 요소가 된다고 하였 다. Lennon et al.(1999)은 외모만족은 객관적인 수 치보다는 주관적인 판단에 의해서 인지되는 경향 이 더 강하고, 객관적인 평가기준이 없을 경우 타 인과 자신과의 비교를 통해 인지된다고 하였다. Lee (2003)는 개인이 자신의 외모가 사회 - 문화적 외모 표준에 가까울수록 더 만족하는 반면, 양자 간 차 이가 클 경우 그 차이를 극복하기 위해 자신의 신 체상을 변화시키려 한다고 하였다. $\operatorname{Kim}(2005)$ 은 아 름다운 외모를 가진 사람은 자기 스스로에게 만족 을 느끼며, 자신감 있는 태도로 사회생활을 하기 때문에 자신의 능력을 더 발휘할 수 있다고 하여 외모만족과 심리적 안녕감 간의 관련성이 있음음 을 시사하였다. Jeong(2006)은 자신의 외모에 만족 하는 사람들이 능동적으로 살아가고, 자신의 능력 을 더 잘 발휘하고, 자신감을 갖게 된다고 하였으 며, Lee(2011)는 외모만족이 사회생활에서 윤활유 역할을 하며, 개인의 생애 전반에 걸쳐 많은 영향 을 준다고 하였다. Kang and Park(2009)은 외모관리 의 성공적 수행이 삶 자체의 변화와 관련될 뿐만 아니라, 외모만족도, 자아존중감 및 전반적인 삶의 만족까지 영향을 미친다고 밝혔다.

한편, 최근 외모에 대한 관심이 급증함에 따라 자 신의 외모에 대해 어떻게 평가하고 있는지 살펴보 기 위해 모바일 설문회사인 두잇 서베이(2012)는 최 근 전국의 남녀 4,931명을 대상으로 '본인의 외모 에 대한 인식'에 관해 조사하였다. 그 결과, 남성의 $34.1 \%$ 가 “내 외모가 괜찮다"고 생각하였으며, 여성 은 $28.6 \%$ 만이 "자신이 예쁘게 생겼다"고 응답했다 고 밝혔다. 연령에 따른 자신의 외모 자신감은 20 대 $30.7 \%, 30$ 대 $32.9 \%, 40$ 대 $33.4 \%$ 로 나이가 많을 수록 외모에 대한 자신감이 높은 것으로 나타났으 나, 50 대 이상부터는 자신감이 급격히 떨어진다고 
보고하였다. 이러한 현상에 대해 조사 관계자는 여 성은 남성에 비해 자신의 신체를 '관찰대상자'로 인 식하게 되어 보다 객관적으로 평가하기 때문에, 자 신의 외모만족도를 더 낮게 평가하는 경향이 있다고 설명하였다(Jang, 2012). 그러나 John and Matthewt (2013/2014)는 개인적인 미의 기준에 관해 설명하 였는데, 매력적인 사람을 만났을 때 처음에는 외모 가 객관적인 평가 기준으로 타인의 평가에 크게 영 향을 주지만, 이 후 그 사람과 상호작용이 발생하 게 되면, 그 사람과의 개인적 경험 혹은 성격 등 여 러 가지 요소들을 통합하여 매력성이 평가되므로 외모에 대한 객관적인 미의 평가보다는 주관적인 미의 중요성을 강조하였다.

이상과 같은 문헌고찰을 토대로 하여 본 연구에 서는 아래와 같은 가설을 설정하였다.

\section{Methods}

\section{Research hypothesis}

가설 1: 자기주장성이 외모만족에 영향을 미칠 것이다.

가설 2: 자기주장성이 심리적 안녕감에 영향을 미칠 것이다.

가설 3. 외모만족이 심리적 안녕감에 영향을 미 칠 것이다.

가설 4. 자기주장성이 외모만족을 매개하여 심 리적 안녕감에 영향을 미칠 것이다.

\section{Data collection and analysis}

본 연구를 위한 자료는 광주광역시에 거주하는 20 30대의 성인여성 500명을 대상으로, 2012년 4 월 23일 5월 13일까지 질문지를 배포하여 수집하 였으며, 회수된 질문지 435 부 중 응답이 불완전한 것을 제외한 359 부를 최종 분석에 이용하였다. 수 집된 자료의 분석을 위해 SPSS for windows 18.0 을 이용하였으며, 빈도분석, 기술통계분석, 요인분석, 회 귀분석, 경로분석을 실시하였다.

\section{Operational of terms and measurements}

1) Psychological well-being
심리적 안녕감은 자기를 있는 그대로 받아들이 고, 원만한 대인관계를 유지하며, 자신의 행동을 스 스로 조절할 수 있고, 주위환경을 통제할 수 있며, 삶에 대한 목적을 가지고 있고, 자신의 인생을 개 선시키려는 의지가 있음을 의미한다. 이를 측정하 기 Kim et al.(2001)이 번안한 Ryff(1989)의 심리적 안녕감 척도(Psychological Well-Being Scale: PWBS) 를 사용하였으며, 예비조사 결과, 신뢰도를 저하시 키는 20 문항을 제외한 총 25 문항을 5 점 척도로 제 시하였다.

\section{2) Self-assertiveness}

본 연구에서 자기주장성은 타인과의 상호작용 과정에서 자기의 의견이나 감정을 언어나 태도 혹 은 행동을 통해 적극적 혹은 소극적으로 표현하는 것을 의미하며, 이를 측정하기 위해 Ha et al.(1983) 이 우리나라 문화권에 맞게 번안한 30문항의 Rathus 의 Assertiveness Scale(1973)을 사용하였으며, 예비 조사 결과, 신뢰도를 저하시키는 4 문항을 제외한 총 26문항을 5점 척도로 제시하였다.

\section{3) Appearance satisfaction}

외모만족은 자신의 전체적인 신체와 신체장식의 결과로 나타나는 외모에 대한 만족 정도를 의미하 며, 이를 측정하기 위해 $\operatorname{Kim}(1984)$ 이 사용한 외모 에 대한 자기만족 6 문항을 5 점 척도로 제시하였다.

\section{Results and Discussion}

\section{The effects of self-assertiveness on appearance} satisfaction

자기주장성이 외모만족에 영향을 미칠 것이라는 가설 1 을 검증하기 위해 먼저 본 연구 자기주장성 정도를 파악하고, 이어 응답자들의 외모만족도를 파 악하였다.

\section{1) Degree of self-assertiveness}

응답자들의 자기주장성의 정도는 〈Table 1〉과 같 다. 총 26 문항의 자기주장성의 평균 점수는 2.92 점 $(\mathrm{N}=359, \mathrm{SD}=.32)$ 로 나타나, 본 연구 응답자들의 자 기주장의 정도는 비교적 높지 않은 것으로 파악되 
었다. 또한 타인을 통해 자신의 의사를 전달한다거 나( $\mathrm{M}=3.56, \mathrm{SD}=.86)$, 바보 취급을 받는 것이 두려 워 모르는 것을 묻지 못한다거나( $\mathrm{M}=3.52, \mathrm{SD}=.85)$, 대화 중 말을 이어가지 못한다 $(\mathrm{M}=3.50, \mathrm{SD}=.86)$ 등
자기주장이 소극적임을 암시하는 문항들에 대한 평균점수는 비교적 높게 나타난 반면, 자신에 대해 좀 더 솔직해지자고 다짐한다거나 $(\mathrm{M}=2.42, \mathrm{SD}=.82)$, 타인의 불친절한 점을 보면 바로 이야기해준다 $(\mathrm{M}=$

$\langle$ Table 1〉 Degree of self-assertiveness

\begin{tabular}{|c|c|}
\hline Items & M(S.D) \\
\hline When I say what I want I convey it to someone A through another $\mathrm{B}(\mathrm{R})$. & $3.56(.86)$ \\
\hline I have avoided asking questions for fear of sounding stupid(R). & $3.52(.85)$ \\
\hline I have some difficulty in going on talking when I converse with others(R). & $3.50(.86)$ \\
\hline I would like to avoid talking when the other sex comes to talk to me(R). & $3.39(.85)$ \\
\hline I am open and frank about my feelings. & $3.35(.80)$ \\
\hline $\begin{array}{l}\text { If a salesman makes a considerable trouble in showing me merchandise which is not quite suitable, I have } \\
\text { some difficulty in saying "No"(R). }\end{array}$ & $3.33(.97)$ \\
\hline Anyone attempting to push ahead of me in a line is in for a good battle. & $3.25(.93)$ \\
\hline $\begin{array}{l}\text { If someone has been spreading false and bad stories about me, I see him(her) as soon as possible to "have } \\
\text { a talk" about it. }\end{array}$ & $3.25(.90)$ \\
\hline I would tell somebody to be quiet who talks loudly around me. & $3.13(.84)$ \\
\hline If I have anything that I want to say, I say it to him or her directly. & $3.13(.78)$ \\
\hline When I have done something important or worthwhile, I manage to let others know about it. & $3.11(.85)$ \\
\hline $\begin{array}{l}\text { If a close and respected relative were annoying me, I would smother my feelings rather than express my } \\
\text { annoyance(R). }\end{array}$ & $3.07(.91)$ \\
\hline I strive to get ahead as well as most people in my position. & $3.07(.81)$ \\
\hline There are times when I look for a good, vigorous argument. & $3.04(.81)$ \\
\hline I often don't know what to say to attractive persons of the opposite $\operatorname{sex}(\mathrm{R})$. & $2.99(.87)$ \\
\hline I often have a hard time saying "No"(R). & $2.97(.94)$ \\
\hline $\begin{array}{l}\text { If a farmed and respected lecturer makes a statement which I think is incorrect, I will have the audience } \\
\text { hear my point of view as well. }\end{array}$ & $2.94(.81)$ \\
\hline I enjoy starting conversations with new acquaintances and strangers. & $2.92(.95)$ \\
\hline $\begin{array}{l}\text { When the food served at a restaurant is not done to my satisfaction, I complain about it to the water or } \\
\text { waitress. }\end{array}$ & $2.85(.86)$ \\
\hline I avoid arguing over price with clerks and salesmen(R). & 2.74(.91) \\
\hline Most people seem to be more aggressive and assertive than I am(R). & 2.74(.82) \\
\hline I trend to bottle up my emotions rather than make a scene(R). & 2.74(.79) \\
\hline I am careful to avoid hurting other people's feelings, even when I feel that I have been injured(R). & $2.68(.81)$ \\
\hline When I am given a compliment, I sometimes just don't know what to say(R). & $2.62(.90)$ \\
\hline I will hesitate to make phone calls to business establishments and institutions(R). & $2.53(.84)$ \\
\hline I am open and frank about my feelings(R). & $2.42(.82)$ \\
\hline Items'mean & $2.92(.32)$ \\
\hline \multicolumn{2}{|l|}{ Cronbach's $\alpha=.68$} \\
\hline
\end{tabular}

(R): reverse items 
$2.85, \mathrm{SD}=.86$ ), 낯선 사람에게 먼저 이야기를 시작 한다 $(\mathrm{M}=2.92, \mathrm{SD}=.95)$ 등 자기주장이 적극적임을 시사하는 문항들에 대한 평균점수는 상대적으로 낮 게 나타났다. 이러한 결과는 초등학교 고학년을 대 상으로 한 연구에서 그들의 자기주장성이 비교적 높은 것으로 나타났다고 밝힌 $\mathrm{Kim}$ and Lee(2008) 의 연구결과와 배치되는 반면, 청년기를 대상으로 한 연구에서 중, 고, 대학생 집단 모두에서는 남성 에 비해 여성이 자기주장성의 어려움을 더 많이 겪 고 있다고 밝힌 Lee(1994)의 연구결과와는 유사성 을 지닌다.

\section{2) Degree of appearance satisfaction}

응답자들의 외모만족 정도는 〈Table 2〉와 같다. 6 개의 외모만족 문항의 표본의 평균점수는 3.08 점 $(\mathrm{N}=359, \mathrm{SD}=.62)$ 으로 모집단의 기대평균 2.5점보다 약간 높은 것으로 나타났으나, 중학생을 대상으로 외모만족도를 파악한 $\operatorname{Kim}(1984)$ 의 연구 결과, 표본 의 평균이 3.14와 비교하면 본 연구 응답자들은 자 신의 외모에 대하여 그다지 만족하고 있지 않은 것 으로 파악되었다. 또한 주관적인 관점에서 자신의 외모가 남에게 좋은 인상을 준다거나 $(\mathrm{M}=3.52)$, 처음 보는 사람에게 호감을 준다거나 $(\mathrm{M}=3.18)$, 이성에게 매력적인 느낌을 준다( $\mathrm{M}=3.03)$ 는 문항에 대해서는
비교적 높은 점수를 나타낸 반면, 타인의 시각을 고 려하여 자신을 더 객관적으로 평가할 수밖에 없는, 모임에서 자신의 외모에 대해 자신감을 갖는다 $(\mathrm{M}=2.99)$, 거울이나 쇼 윈도우에 비친 자신의 모습 에 대해 만족한다( $\mathrm{M}=2.94)$, 친구들이 자신의 외모 를 부러워한다 $(\mathrm{M}=2.83)$ 는 문항에 대한 점수는 평 균 이하인 것으로 나타났다. 이러한 결과는 타인이 나 객체적인 자기 즉 자신 안에 내재된 타인의 관 점에서 자신의 외모를 바라볼 때 더 비판적인 시각 을 갖게 되기 때문으로 해석된다.

\section{3) The effects of self-assertiveness on appearance} satisfaction

자기주장성이 외모만족에 영향을 미칠 것이라는 가설 1 을 검증하기 위해 자기주장성을 독립변인으 로, 외모만족을 종속변인으로 하여 회귀분석을 실 시한 결과는〈Table 3〉과 같이 나타났다.

자기주장성이 외모만족을 설명한 총 변량은 $4.1 \%$ 로 파악되었으며, 이것이 외모만족에 통계적으로 유의한 정적 $(+)$ 영향 $(F=15.199, t=3.899, p<.001)$ 을 미치는 것으로 나타났다. 이러한 결과는 외모만족 에 미치는 자기주장성의 영향이 크지는 않지만, 이 것이 자기주장성이 강할수록 외모에 대한 만족도 가 높다는 것을 의미하며, 자기주장성행동이 적극

$\langle$ Table 2〉 Degree of appearance satisfaction

\begin{tabular}{|c|c|}
\hline Items & $\mathrm{M}(\mathrm{S} . \mathrm{D})$ \\
\hline My appearance tends to makes good impression on others. & $3.52(.73)$ \\
\hline I think my appearance makes a favorable impression on other people when I meet them for the first time. & $3.18(.78)$ \\
\hline I think my appearance makes me attractive to the opposite sex. & $3.03(.80)$ \\
\hline I am confident about my looks when I am in a group. & $2.99(.82)$ \\
\hline I am satisfied with my reflection in the mirror. & 2.94(.81) \\
\hline My friends tends to envy my appearance. & $2.83(.83)$ \\
\hline Items'mean & $3.08(.62)$ \\
\hline Cronbach's $\alpha=.68$ & \\
\hline
\end{tabular}

$\langle$ Table 3〉 The effects of self-assertiveness on appearance satisfaction

\begin{tabular}{c|c|c|c|c|c|c|c|c}
\hline Independent variables & Dependent variables & B & S.E & $\beta$ & $t$ & $F$ & $R^{2}$ \\
\hline Self-assertiveness & Appearance satisfaction & .389 & .100 & .202 & $3.899 * * *$ & $15.199 * * *$ & .041 \\
\hline$* * * p<.001$
\end{tabular}


적이고 자기주장성 욕구가 높을수록 의복관심을 포 함하여 자신의 외모에 긍정적인 태도를 나타냈다 고 밝힌 Jeong(2004)의 연구결과와 상통한다. 또한 고등학생을 대상으로 한 연구에서 외모만족도와 자 기주장성 간 정적인 상관관계가 존재하며, 외모에 대한 만족도가 높을수록 자기주장성이 높은 것으 로 나타났다고 밝힌 $\operatorname{Kim}(2005)$ 의 연구결과와 맥을 같이 하며, 자신의 외모에 대한 만족도가 높을수록 타인과의 관계에서 자신의 감정이나 경험 등을 자 연스럽게 표현한다고 밝힌 Kim and Lee(2008)의 연구결과를 지지한다.

결과적으로, 자기주장성이 외모만족에 영향을 미 칠 것이라는 가설 1 은 채택되었다.

\section{The effects of self-assertiveness on psy-} chological-wellbeing

자기주장성이 심리적 안녕감에 영향을 미칠 것 이라는 가설 2 를 검증하기 위해 먼저 본 연구 응답 자들의 심리적 안녕감의 차원을 분류하였다.

\section{1) Factors of psychological well-being}

심리적 안녕감의 차원을 분류하기 위해 심리적 안녕감에 관한 25 문항을 Varimax 회전법을 사용하 여 요인분석 한 결과는 〈Table 4〉와 같다.

고유치 1이상인 6 개의 차원이 도출되었으며, 6 요인의 신뢰도 계수(Cronbach's $\alpha$ )는 각각 $.84, .85$, $.71, .72, .70, .64$ 로 나타나, 문항 간 내적 일관성이 확보되었다. 각 요인들이 심리적 안녕감을 설명한 총 변량은 $61.50 \%$ 로 나타났다.

요인 1 은 전체변량의 $21.41 \%$ 를 설명하였고, 이 요인에는 자신이 살아온 인생과 생활방식의 개선 및 자신의 발전에 관한 문항들이 포함되었기 때문 에 “개인적 성숙"으로 명명하였다. 요인 2는 전체 변량의 $13.38 \%$ 를 설명하였고, 이 요인에는 미래에 대한 계획, 인생의 목표 등에 관한 문항들이 포함 되었기 때문에 “삶의 목적의식”이라 명명하였다. 요인 3은 전체변량의 $8.35 \%$ 를 설명하였고, 이 요인 에는 자신이 살아온 인생의 결과에 만족, 자신에 대한 긍정적 시선 등에 관한 문항들이 포함되었기 때문에 “자기수용”이라 명명하였다. 요인 4는 전체 변량의 $7.06 \%$ 를 설명하였고, 일상생활에서의 자신
의 책임, 시간활용, 경제적 문제 등의 수행과 관리 에 관한 문항들이 포함되었기 때문에 “환경통제”로 명명하였다. 요인 5 는 전체 변량의 $6.23 \%$ 를 설명하 였고, 타인과의 관계에서 자신의 의견이나 견해 등 을 표현하는 것에 관한 문항들이 포함되어 있어 “자율성”이라 명명하였다. 마지막으로 요인 6은 전 체변량의 $5.07 \%$ 를 설명하였고, 친구들이나 타인과 의 관계에 관한 문항들이 포함되어 있기 때문에“대 인관계"로 명명하였다.

이러한 결과는 심리적 안녕감을 자아수용, 긍정 적 대인관계, 자율성, 환경에 대한 지배력, 삶의 목 적 및 개인적 성장으로 분류했던 $\operatorname{Ryff(1989)}$ 의 결 과와 Ryff의 측정도구를 우리나라 성인남녀에게 적 용하여 6개의 요인을 확증했던 Kim et al.(2001)의 연구결과와 일치한다.

2) The effects of self-assertiveness on psychological-wellbeing

자기주장성이 심리적 안녕감에 영향을 미칠 것 이라는 가설 2 를 검증하기 위해 자기주장성을 독립 변인으로, 심리적 안녕감을 종속변인으로 하여 회 귀분석을 실시한 결과는 〈Table 5〉와 같이 나타났다.

전체적으로, 자기주장성이 심리적 안녕감을 설 명한 총 변량은 $4.6 \%$ 로 파악되었으며, 자기주장성 이 심리적 안녕감에 통계적으로 유의한 정적(+) 영 향 $(F=17.320, t=4.162, p<.001)$ 을 미치는 것으로 나 타났다. 구체적으로, 자기주장성은 심리적 안녕감 차 원들 중 자율성 $(\beta=.300, t=5.949, p<.001)$, 삶의 목적 의식 $(\beta=.162, t=3.108, p<.01)$ 및 환경통제 $(\beta=.146$, $t=2.779, p<.01)$ 차원 순으로 유의한 영향을 미쳤다.

이러한 결과는 자기주장성이 높을수록 타인에게 자신의 의견을 자유롭게 전달하고, 인생의 목표의 식이 비교적 뚜렷하고, 시간이나 경제문제 등을 잘 통제하고, 타인과 긍정적인 관계를 유지한다는 것 을 의미한다. 이는 타인에게 자신을 노출할 수 있 는 사람이 대인관계가 원만하고 정신적으로 건강 하고, 생산적이고 능률적인 생활을 할 수 있다고 한 Hekmat and Vanian(1971)의 주장을 부분적으로 뒷 받침한다. 또한 자신의 감정과 입장을 솔직하고 적 절하게 표현할 줄 아는 사람들이 그렇지 못한 사람 들보다 더 건강하고 행복한 삶을 누릴 수 있을 뿐 
$\langle$ Table 4〉 Factors of psychological-wellbeing

\begin{tabular}{|c|c|c|c|c|}
\hline Items & $\begin{array}{l}\text { Factor } \\
\text { loading }\end{array}$ & $\begin{array}{c}\text { Eigen } \\
\text { value } \\
(\% \text { of } \\
\text { variance })\end{array}$ & $\begin{array}{c}\text { Cumu- } \\
\text { lative } \\
(\%)\end{array}$ & $\begin{array}{c}\text { Cron- } \\
\text { bach's } \\
\alpha\end{array}$ \\
\hline $\begin{array}{l}\text { Factor 1: Personal growth } \\
\text { - I gave up trying to make big improvements or change in my life a long time ago(R). } \\
\text { - I am not interested in activities that will expand my horizons(R). } \\
\text { - There is truth to the saying you can't teach an old dogs new tricks(R). } \\
\text { - I don't want to try new ways of doing things my life is fine the way it is(R). } \\
\text { - When I think about it, I haven't really improved much as a person over the years(R). }\end{array}$ & $\begin{array}{l}.927 \\
.922 \\
.742 \\
.619 \\
.559\end{array}$ & $\begin{array}{c}5.35 \\
(21.41)\end{array}$ & 21.41 & .84 \\
\hline $\begin{array}{l}\text { Factor 2: Purpose in life } \\
\text { - I have life one day at a time and don't rally think about the future(R). } \\
\text { - I enjoy making plans for the future and working to make them a reality. } \\
\text { - Some people wander aimlessly through life but I am not one of them. } \\
\text { - I try to carry out the plans I set for myself despite any difficulty. }\end{array}$ & $\begin{array}{l}.893 \\
.869 \\
.776 \\
.672\end{array}$ & $\begin{array}{c}5.34 \\
(13.38)\end{array}$ & 34.78 & .85 \\
\hline $\begin{array}{l}\text { Factor 3: Self- acceptance } \\
\text { - When I look at the story of my life, I am pleased with how things have turned out so far. } \\
\text { - I made some mistakes in the past, but I feel that all in all everything has worked out for the best. } \\
\text { - I like most aspects of my personality. } \\
\text { - When I compare myself to friends and acquaintances, it makes me feel good above who I am. }\end{array}$ & $\begin{array}{l}.776 \\
.668 \\
.637 \\
.627\end{array}$ & $\begin{array}{c}2.09 \\
(8.35)\end{array}$ & 43.13 & .71 \\
\hline $\begin{array}{l}\text { Factor 4: Environmental mastery } \\
\text { - I am good at managing the responsibilities of daily life. } \\
\text { - I am good at juggling my time so that I can fit everything in that needs to get done. } \\
\text { - I generally do a good job of talking care of my personal finances and affairs. } \\
\text { - I have difficulty arranging my life in a way that is satisfying to me(R). }\end{array}$ & $\begin{array}{l}.742 \\
.736 \\
.606 \\
.597\end{array}$ & $\begin{array}{c}1.77 \\
(7.06)\end{array}$ & 50.20 & .72 \\
\hline $\begin{array}{l}\text { Factor 5: Autonomy } \\
\text { - I am not afraid to avoid voice my opinions, even when they are in opposition to the opinions } \\
\text { of most people. } \\
\text { - I often change my mind about decisions if my friends or family disagree(R). } \\
\text { - It's difficult for me to voice my opinions on controversial matters(R). } \\
\text { - I tend to be influenced by people with strong opinions(R). }\end{array}$ & $\begin{array}{l}.839 \\
.804 \\
.658 \\
.474\end{array}$ & $\begin{array}{c}1.56 \\
(6.23)\end{array}$ & 56.42 & .70 \\
\hline $\begin{array}{l}\text { Factor 6: Interpersonal relations } \\
\text { - I often feel lonely because I have few close friends with whom to share my concerns(R). } \\
\text { - I have not experienced many warm and trusting relationships with others(R). } \\
\text { - I don't have many people who want to listen when I need to talk(R). } \\
\text { - I know I can trust my friends, and they know they can trust me. }\end{array}$ & $\begin{array}{l}.751 \\
.703 \\
.627 \\
.478\end{array}$ & $\begin{array}{c}1.27 \\
(5.07)\end{array}$ & 61.50 & .64 \\
\hline
\end{tabular}

(R):reverse items

$\langle$ Table 5〉 The effects of self-assertiveness on psychological well-being

\begin{tabular}{c|c|c|c|c|c|c|c|c}
\hline Independent variables & Dependent variables & $\mathrm{B}$ & $\mathrm{S} . \mathrm{E}$ & $\beta$ & $t$ & $F$ & $R^{2}$ \\
\hline \multirow{5}{*}{ Self-Assertiveness } & Personal growth & .019 & .115 & .009 & .169 & .029 & .000 \\
\cline { 2 - 9 } & Purpose in life & .357 & .115 & .162 & $3.108^{* *}$ & $9.662 * *$ & .026 \\
\cline { 2 - 9 } & Self-acceptance & .171 & .097 & .093 & 1.762 & 3.103 & .009 \\
\cline { 2 - 9 } & Environmental mastery & .286 & .103 & .146 & $2.779 * *$ & $7.723^{* *}$ & .021 \\
\cline { 2 - 9 } & Autonomy & .505 & .085 & .300 & $5.949 * * *$ & $35.391 * * *$ & .090 \\
\cline { 2 - 9 } & Interpersonal relations & .440 & .090 & .170 & 1.928 & 3.718 & .010 \\
\hline \multirow{2}{*}{ Total } & Total & .254 & .061 & .215 & $4.162 * * *$ & $17.320^{* * *}$ & .046 \\
\hline
\end{tabular}

$* * p<.01, * * * p<.001$ 
만 아니라, 타인과의 의사소통과정에서 서로 간의 갈등과 오해를 줄임으로써 대인관계의 질을 향상 시킬 수 있을 것이라는 $\operatorname{Hong}(1998)$ 의 유추와 자기 표현력이 높을수록 주관적 삶의 만족도 및 심리적 안녕감이 크다고 밝힌 $\operatorname{Eom(2001)ㅇㅢ~ㅇㅕㄴㄱㅜㄱㅕㄹㄱㅘㄹㅡㄹ~ㅈㅣ~}$ 지한다.

결과적으로, 자기주장성이 심리적 안녕감에 영 향을 미칠 것이라는 가설 2는 채택되었다.

\section{The effects of appearance satisfaction on} psychological well-being

외모만족이 심리적 안녕감에 영향을 미칠 것이 라는 가설 3 을 검증하기 위하여 외모만족을 독립변 인으로, 심리적 안녕감을 종속변인으로 하여 회귀 분석을 실시한 결과는 〈Table 6〉과 같이 나타났다.

외모만족이 심리적 안녕감을 설명한 총 변량은 $4.3 \%$ 로 파악되었으며, 외모만족이 심리적 안녕감 에 통계적으로 유의한 정적 $(+)$ 영향 $(F=16.216, t=4.027$, $p<.001)$ 을 미치는 것으로 나타났다. 이러한 결과는 외모만족이 심리적 안녕감에 큰 영향을 미치지 않 지만, 응답자들의 외모만족도가 높을수록 심리적 안 녕감이 높다는 것을 의미하며, 자신의 외모를 매력 적으로 평가할수록 주관적 안녕감이 더 높다고 밝 힌 Kim et al.(2006)의 연구결과와 자신의 신체매력 을 긍정적으로 지각할수록 심리적 건강의 수준이 높다고 밝힌 Lee(2011)의 연구결과와 일맥상통한다.

외모만족이 심리적 안녕감의 각 차원에 미치는 구체적인 영향을 살펴보면, 자기수용 $(\beta=.286, t=5.639$, $p<.001)$, 삶의 목적의식 $(\beta=.214, t=4.148, p<.001)$,
환경통제 $(\beta=.190, t=3.652, p<.001)$, 자율성 $(\beta=.162$, $t=3.094, p<.01)$ 차원에 각각 유의한 영향을 미친 반 면, 대인관계 차원과 개인적 성숙 차원에는 통계적 으로 유의한 영향을 미치지 않는 것으로 나타난 결 과가 주시된다. 이러한 결과는 외모에 대한 만족이 자신에 대한 긍정적 시선, 미래에 대한 계획, 일상 생활의 책임 있는 관리 및 자신의 표현에는 영향을 미치지만, 삶의 방식을 바꾸어 인생을 개선하겠다 는 의지를 갖게 한다거나, 대인관계에서 느끼는 외 로움이나 소외감을 극복하는 데에는 별 영향을 미 치지 않는다는 것을 의미한다. 이는 남녀 고등학생 을 대상으로 한 연구에서 외모만족도가 심리적 안 녕감의 많은 부분을 설명한다고 밝힌 Gong(2009) 의 결과, 자신의 외모에 만족함으로 심리적 안녕감 이 높다고 밝힌 $\mathrm{Ju}(2011)$ 의 결과와 일맥상통한다.

결과적으로, 외모만족이 심리적 안녕감에 영향을 미칠 것이라는 가설 3 은 채택되었다.

\section{The effects of self-assertiveness on psy-} chological well-being mediated appearance satisfaction

자기주장성이 외모만족을 매개하여 심리적 안녕 감에 영향을 미칠 것이라는 가설 4 를 검증하기 위 해 자기주장성을 독립변인으로 외모만족을 매개변 인으로 하고, 심리적 안녕감을 종속변인으로 하여 경로분석을 실시한 결과는 〈Table 7〉, 〈Fig. 1〉과 같 이 나타났다.

자기주장성이 심리적 안녕감에 미친 직접효과는 .215 로 나타났고, 외모만족을 매개하여 심리적 안

$\langle$ Table 6〉 The effects of appearance satisfaction on psychological well-being

\begin{tabular}{c|c|c|c|c|c|c|c}
\hline Independent variables & Dependent variables & $\mathrm{B}$ & $\mathrm{S} . \mathrm{E}$ & $\beta$ & $t$ & $F$ & $R^{2}$ \\
\hline \multirow{5}{*}{ Appearance satisfaction } & Personal growth & -.041 & .060 & -.037 & -.694 & .481 & .001 \\
\cline { 2 - 9 } & Purpose in life & .245 & .059 & .214 & $4.148^{* * *}$ & $17.206^{* * *}$ & .046 \\
\cline { 2 - 9 } & Self-acceptance & .275 & .049 & .286 & $5.639 * * *$ & $31.798^{* * *}$ & .082 \\
\cline { 2 - 9 } & Environmental mastery & .194 & .053 & .190 & $3.652^{* * *}$ & $13.338^{* * *}$ & .036 \\
\cline { 2 - 9 } & Autonomy & .141 & .046 & .162 & $3.094^{* *}$ & $9.572^{* *}$ & .026 \\
\cline { 2 - 9 } & Interpersonal relations & .047 & .050 & -.049 & -.933 & .870 & .002 \\
\hline \multirow{2}{*}{ Total } & Total & .128 & .032 & .208 & $4.027 * * *$ & $16.216^{* * *}$ & .043 \\
\hline
\end{tabular}

$* * p<.01, * * * p<.001$ 
$\langle$ Table 7$\rangle$ The direct effect $\cdot$ indirect effects of self-assertiveness on psychological well-being mediated appearance satisfaction

\begin{tabular}{c|c|c|c|c}
\hline Independent variables & Dependent variables & D.E & I. E & T.E \\
\hline Self-assertiveness & \multirow{2}{*}{ Psychological well-being } & .215 & $(.202 \times .208)=.042$ & .257 \\
\cline { 1 - 3 } Appearance satisfaction & & .208 & - & .208 \\
\hline
\end{tabular}

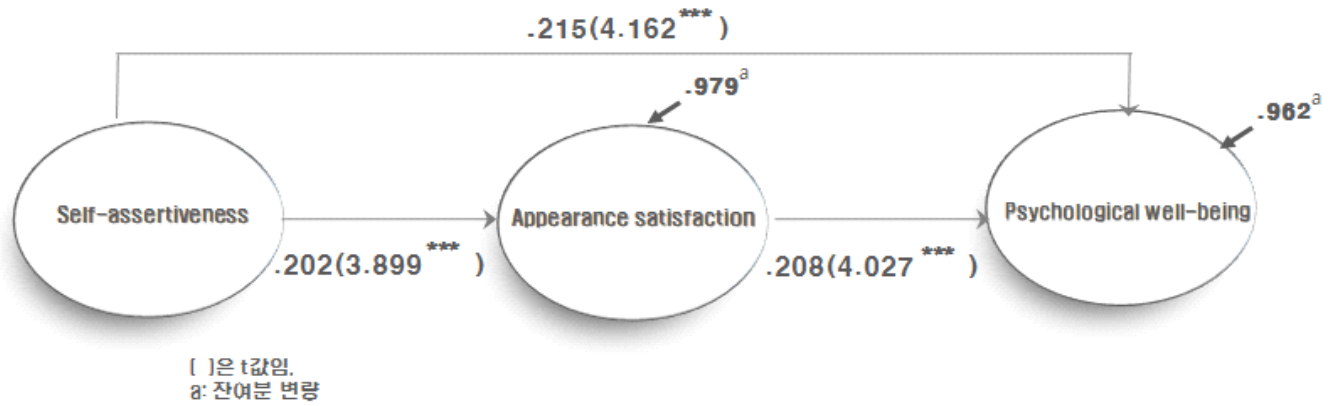

〈Fig. 1〉 The effects of self-assertiveness on psychological well-being mediated appearance satisfaction.

녕감에 미친 간접효과는 .042(.202×.208)로 나타나, 통계적으로 유의하지 않은 것으로 파악되었다. 한 편, 외모만족이 심리적 안녕감에 미치는 직접 효과 는 .208로 나타나, 외모만족이 심리적 안녕감을 설 명하는데 있어서 더 중요한 직접적인 영향요인이 라는 것이 파악되었다. 이는 자기주장성이 외모만 족을 매개하지 않고 독립적으로 심리적 안녕감에 영향을 미친다는 것을 의미하는 것으로, 자기주장 성과 외모만족이 심리적 안녕감에 영향을 미치는 과정에서 두 변인들 간 인과관계가 존재하지 않는 다는 것으로 파악된다. 이러한 결과는 자기주장성 이 타인과의 커뮤니케이션에서 자신의 의견이나 감정을 언어적 혹은 비언어적 표현을 통해 전달하 는 것으로, 자기주장성이 높은 여성일 경우, 타인에 게 자신의 생각을 적극적으로 표현함으로써 자신 감을 얻게 되어 주관적으로 자신의 외모까지도 긍 정적으로 지각할 뿐만 아니라, 사회 구성원으로서 의 제 역할을 수행하며, 스스로 자신의 삶을 통제 하고 개선할 수 있다는 심리적인 안녕감을 느끼는 것으로 해석된다. 주시되는 것은 타인과의 상호작 용 속에서 비록 자기주장을 적극적으로 표현하지 못할지라도 자신의 외모를 긍정적으로 지각하고 타인에게 인정 받아 외모에 대한 만족감이 높아진다
면 이러한 심리적 안녕감을 높일 수 있는 것으로 해석된다.

결과적으로, 자기주장성이 외모만족을 매개하여 심리적 안녕감에 영향을 미칠 것이라는 가설 4는 채택되지 않았다.

\section{Conclusion}

본 연구는 언어적 - 행동적 자기제시로 볼 수 있 는 자기주장성과 비언어적 자기제시의 선행요건인 외모관리행동의 결과에 따른 외모만족이 심리적 안 녕감에 미치는 영향을 파악하기 위한 목적으로 수 행되었으며, 자료를 분석하여 얻은 결과는 다음과 같다.

첫째, 응답자들의 외모만족 정도는 비교적 낮은 것으로 파악되었고, 자기주장성이 외모만족에 유의 한 영향을 미치는 것으로 나타났다. 둘째, 심리적 안녕감은 개인적 성숙, 삶의 목적의식, 자기수용, 환경통제, 자율성, 대인관계라는 6 요인으로 분류되 었고, 자기주장성이 전체적인 심리적 안녕감에 유 의한 영향을 미치는 것으로 나타났으나, 차원별 심 리적 안녕감에 미치는 영향은 부분적으로만 유의 한 것으로 나타났다. 셋째, 외모만족이 전체적인 심 
리적 안녕감에 유의한 정적 영향을 미치는 것으로 나타났으나, 차원별 심리적 안녕감에 미치는 영향 은 부분적으로만 유의한 것으로 나타났다. 넷째, 자 기주장성이 외모만족을 매개하여 심리적 안녕감에 미치는 영향은 유의하지 않은 것으로 나타났다.

이상과 같은 결과들은 심리적 안녕감 증진을 위 해서는 먼저 자기의 의견이나 감정 등을 억제하지 않고, 적극적으로 표현할 수 있어야 하며, 자신의 외모에 대해 긍정적인 시각을 갖는 것과 적절한 외 모관리가 필요하다는 것을 시사한다. 따라서 연구 자들이 여성들의 심리적 안녕감 증진을 위한 프로 그램 개발 시 언어나 행동을 통한 자기주장성 훈련 뿐만 아니라, 외모관련 주제를 포함시킬 필요가 있 을 것으로 사료된다.

본 연구의 의의는 20 30대 여성들의 언어적, 행 동적 자기제시로 볼 수 있는 자기주장성과 비언어 적 상징인 외모에 대한 만족이 그들의 심리적 안녕 감에 미치는 영향을 경험적으로 구명한 데에 있다. 그러나 자기주장성과 외모만족이 각각 심리적 안 녕감을 설명할 수 있는 변량이 크지 않은 것으로 나타난 결과는, Lee and Park(2013)의 연구에서 자 아와 자신의 신체에 대해 만족하는 사람은 삶의 만 족 또한 높은 것으로 파악된 결과에 비추어 볼 때, 자아존중감이나 자기효능감 등의 심리적 변인이나 개인의 외모에 대한 태도(ex: 외모비교, 외모통제, 외모수치심, 외모감시, 객체화된 신체의식 등)의 변 인이 존재한다는 것을 유추케 하는 바, 여성들의 심리적 안녕감에 영향을 미칠 개연성이 있는 여타 의 변인들 추후 심리적 안녕감 증진에 도움이 되는 행동이나 활동유형을 탐색하기 위한 더 나아간 연 구가 필요할 것으로 보인다. 특히 Ryff가 개발한 심 리적 안녕감의 측정 도구를 우리나라에 적용했을 때, 우리나라의 선행연구 뿐만 아니라, 본 연구의 결과에서도 많은 문항들이 신뢰도와 타당도가 결 여되었다. 따라서 미래 연구에서는 우리나라 실정 에 맞는 심리적 안녕감의 측정도구를 개발하여 적 용할 필요가 있을 것으로 사료된다. 또한 본 연구 가 일부지역에서 편의 추출한 여성들만을 대상으 로 했다는 제한점을 지니기 때문에 연구결과의 일 반화 가능성을 확인하기 위해서는 다양한 연령대 의 여성들을 대상으로 한 연구를 필요로 한다.

\section{References}

Albert R. E., \& Emmons, M. L.(1975). Stand up, speak out, talk back!: The key to self-assertive behavior. New York: Pocket Books.

Audrey Ann Glenn, B. A.(1980). Use of assertiveness training and cue-controlled desensitization for assertion problems with women. The Ohio State University.

Bae, S. Y., \& Park, K. S.(2011), A study on nail management behavior based on psychological wellness: Focusing on women engaged in sales and services. Research Journal of the Costume Culture, 19(6), 1235-1246.

Bornstein, M. R., Bellack, A. S., \& Hersen, M.(1977). Social- skill training for unassertive children: A Multiple - baseline analysis. Journal of Applied Behavior Analysis, 10(2), 183-195.

Chung, K. J.(2004). Effect of self-disclosure on appearance management behavior and body exposure in clothing behavior. Unpublished master's thesis, Yonsei University, Seoul, Korea.

Diener, E.(1984). Subjective well-being. Psychological Bulletin, 95(3), 542-575.

Eom, E. M.(2001). The effect of an assertive training program on the anger expression, Self-assertiveness and psychological wellbeing; Fousing on elementary school students in Korea. Unpublished master's thesis, Korea University, Seoul, Korea.

Gong, Y. G.(2009). The effects of appearance satisfaction and social support on psychological wellbeing: The effects of rejection sensitivity of as mediator. Unpublished master's thesis, Hanyang University, Seoul, Korea.

Ha, Y. S.(1991). The effect of a group reminiscence on the psychological well-being of the elderly. Unpublished doctoral dissertation, Seoul University, Seoul, Korea.

Ha, Y. S., Kim, S. H., Mun, C. H., Sok, S. Y., Yoon, J. L., \& Lee, M. J.(1983). The assertivenss training program for aggressive or passive under- 
graduates. Journal of Student Guidance, 16(1), $1-50$.

Havighurst, R. J.(1972). Developmental task and education(3th ed.). N. Y.: David Mckay Co.

Hekmat, H., \& Vanian, D.(1971). Behavior modification through covert semantic desensitization. Journal of Consulting and Clinical Psychology, 36(2), 248-251.

Heo, Y. M.(2007). A study on the relationship between career attitude maturity and psychological independence, self-assertion and self-concept. Unpublished maser's thesis, Sogang University, Seoul, Korea.

Hong, G. J.(1981). A study on assertiveness training of validity for Korean university students. Chonnam National University of Journal of Student Guidance, 31, 81-90.

Hong, G. J., \& Rho, A. Y.(1983). The effects of assertive training on the reduction of aggression and anxiety in juvenile delinquents. Korean Journal of Clinical Counseling Psychology, 4(1), 19-31.

Hong, M. S.(1998). Effects of assertiveness training on self-expression, interpersonal support evaluation and psychological well being. Unpublished master's thesis, Kyungnam University, Masan, Korea.

Hwang, J. S., \& Kim, Y. H.(2006). The effect of appearance management on body image and psychological well-being. Journal of the Korean Society of Costume, 56(3), 143-155.

Jang, M. S.(2012, December 10). Difference of male and female: an objective evaluation. TV Roport, Retrieved Octover 21, 2014, from, http://www. tvreport.co.kr/?c=news\&m=newsview\&idx $=289584$

Jeong, K. H.(2006). The influence of make-up on the image effect: Women in twenties. Unpublished maser's thesis, Sookmyung Women's University, Seoul, Korea.

John, N., \& Matthew, K.(2014). Compelling people: The hidden qualities that make us influential( $\mathrm{P} . \mathrm{Su}$, Seong.). Seoul: Tornado.(Original work published 2013)

Ju, K. S.(2011). A study on the effects of adolescents' appearance satisfaction and self-esteem on the psychological well-being: Focusing on the relevance with 6PF. Unpublished master's thesis, Segang University, Seoul, Korea.

Jung, H. J., Kim, H. Y., \& Lee, Y. R.(2008). Transactions: The buying behavior for school uniforms according to adolescents` assertiveness and appearance concerns. Journal of the Korean Society of Clothing and Textiles, 32(5), 777-787.

Kaiser, S. B.(1990). The social psychology of clothing: Symbolic appearance in context(2nd ed.). New York: Macmillan Publishing.

Kang, Y. S., \& Park, H. J.(2009). The relationship between body image and self-esteem toward appearance care behavior of beauty salon customer: Focused on 20's customer in Daegu. Journal of The Korean Society of Cosmetology, 15(1), 363373.

Kim, D. I.(2011). The relationship among participation motivation, self-management behaviors, self-expressions, and life satisfaction of female participants in dance sport. Unpublished doctoral dissertation, Korea National Sport University, Seoul, Korea.

Kim, E. H.(1993). The effects of assertiveness training on the enhancement of assertive behavior of nursing students. Journal of Korean Academy of Psychiatric and Mental Health Nursing, 2, 6375.

Kim, G. R.(2008). Elementary school student's appearance recognition on the self-expression and interpersonal anxiety. Unpublished master's thesis, Ewha Womans University, Seoul, Korea.

Kim, G. R., \& Lee, W. J.(2008). Children's appearance interests and satisfaction according to the selfexpression and the interpersonal anxiety. Journal of Korean Council for Children \& Rights, 12(4), 567-584.

Kim, G. S.(2006). The development and application of a program for college students psychological well-being. Unpublished doctoral dissertation, Kyungsung University, Busan, Korea. 
Kim, H. C.(2004). 웰빙마케팅: 한국형 비지니스의 새로운 패러다임 [Well-being marketing]. Seoul: Come on books.

Kim, H. O.(2010). The effect of children's social network on self-perceived competence, ego-resiliency and psychological well-being. Unpublished doctoral dissertation, Dongduk Women's University, Seoul, Korea.

Kim, J. J., Koo, J. Y., \& Suh, E. K.(2006). Physical attractiveness and happiness come together? The Korean Journal of Social \& Personality Psychology, 20(4), 61-70.

Kim, M. S., Kim, H. W., \& Cha, G. H.(2001). Analyses on the construct of psychological well-being (PWB) of Korean male and female adults. The Korean Journal of Social and Personality Psychology, 15(2), 19-39.

Kim, M. Y.(1984). A study on the abolition of school uniforms and personal appearance satisfaction among junior and senior high school girls. Unpublished master's thesis, Sang Myung's University, Seoul, Korea.

Kim, S. H.(2005). The relationships among appearance satisfaction, interpersonal relations, self-assertion, and academic achievement of high school students. Unpublished master's thesis, Kangwon National University, Kangwon, Korea.

Kim, S. N., \& Lee, K. S.(2007). Theses: A research of appearance management behavior in $20 \sim 40$ 's women according to degree of appearance concern. Journal of Fashion Business, 11(4), 29-41.

Kwon, O. I.(2008). Relationship among physical selfconcept, cognitive freedom and psychological wellbeing in leisure sports participants. Unpublished doctoral dissertation, Myongji University, Seoul, Korea.

Lawrence, F. S.(1970). The assesment and modification of assertive behavior. (Doctoral Dissertation, Arizona State University, 1979). Dissertation Abstracts International, 31, 1B-971B.

Lazarus, A. A.(1971). Behavior therapy and beyond.
New York: McGraw-Hill.

Lee, E. S.(2011). The influence of perception of physical attractiveness on health promoting behavior and appearance management behavior. Journal of the Korean Home Economics Association, 49(6), 47-56.

Lee, G. W.(1994). The effects of body image on selfsatisfaction, anxiety and self-expression in adolescence. Unpublished master's thesis, Ewha Womans University, Seoul, Korea.

Lee, J. Y., \& Park, H. J.(2013). Effects of self-esteem, physical appearance comparison, and media concern on sociocultural attitude toward appearance, body attitudes, and life satisfaction. Journal of the Korea Fashion \& Costume Design Association, 15(3), 1-17.

Lee, K. H.(2011). The analysis of effects of university students' depression and self-efficiency on the trends of personal relationship: verification of parametric effects of appearance satisfaction. Unpublished doctoral dissertation, Hanseo University, Seosan, Korea.

Lee, S. G.(2003). Formation models of body image, self-esteem, and clothing attitudes as related to pubertal physical growth. Unpublished doctoral dissertation, Yonsei University, Seoul, Korea.

Lee, Y. J.(2010). Research on types of the old caring appearances according to their self-esteem and perception of physical attraction. Unpublished doctoral dissertation, Daegu University, Daegu, Korea.

Lennon, S. J., Rudd, N. A., Sloan, B., \& Kim, J. S. (1999). Attitudes toward gender roles, self-esteem, and body image: Application of a model. Clothing and Textiles Research Journal, 17(4), 191-202.

Mung, H. J., \& Park, K, S.(2013). Research paper: The influence of the mid aged women's selfexpression and appearance complex on appearance management behavior. Korean Beauty Society, 19(3), 532-544.

Myerson, L.(1971). Somatopsychology of physical disability. In Cruickshank(Ed.). Psychology of exceptional children and youth. Englewood Cliffs, 
Prentice Hall, New Jersey.

Rathus, Spencer. A.(1972). An experimental in a group setting. Journal of Behavior Therapy \& Experimental Psychiatry, 3(2), 81-86.

Ryff, C. D.(1989). Happiness is everything, or It is ploration the meaning of psychological well-being. Journal of Personality and Social Psychology, 57(6), 1069-1081.

Salter, A.(1949). Condioned reflex therapy. New York: Capricon Books. published by Wellness Institute (2002).

Song, M. S.(1992). A study on the assertiveness of college students. Unpublished master's thesis, Yonsei University, Seoul, Korea.

Song, S. W., \& Yon, M. H.(2008). A qualitative study of college students` change experiences of selfassertiveness improvement group counseling. Korea Journal of Counseling, 9(4), 1641-1663.

Sung, Y. S.(1997). 소비자 광고 속의 신체이미지: 아름 다움의 담론 [Body image of in consumer adver- tising: The discourse of beauty]. Seoul: Sahoebipyeong.

Thompson, J, K., \& Stice, E.(2001). Thin ideal internalization: Mounting evidence for a new risk for body Image disturbance and eating disturbance and eating pathology. Current Directions in Psychological Science, 10(5), 181-183.

Wolpe, J., \& Lazarus, A. A.(1966) Behavior therapy techniques: A guide to the treatment of neuroses. Oxford: Pergamon Press.

Yang, M. H.(1998b). Physical activity and psychological well-being: Development of improving cognitive and emotive state. Korean Journal of Sport Psychology, 9(2), 113-124.

Yook, K. Y., Yun, J. W., Kim, K. H., Suh, S. Y., \& Park, J. H.(2009). The relationship between bodyimage discrepancy and psychological well-being in female college students. The Korean Journal of Woman Psychology, 14(4), 665-682. 